\section{Absence of specific retroactive interference effects of acoustic similarity in short-term memory*}

\author{
J. JEFFREY LAVERTY and M. T. TURVEY† \\ University of Connecticut, Storrs, Conn. 06268
}

Each of 24 Ss received acoustically similar or different pairs of tetragrams separated by 2.5 or $18 \mathrm{sec}$ of interpolated activity. Level of recall for the first tetragram after an interval of $20.5 \mathrm{sec}$ was not significantly affected by the acoustic similarity of the second tetragram or the time elapsing between the tetragrams. A significant interaction was found, however, between these factors. Simultaneous presentation of tetragram consonants as opposed to sequential presentation appeared to underlie the absence of specific retroactive interference effects and the obtained interaction. The data question the generality of acoustic similarity effects in short-term memory.

In contrast to the abundant evidence for specific proactive interference (PI) effects in short-term memory (STM) due to item similarity, similar evidence for specific retroactive-interference (RI) effects is sparse (see Posner, 1967). Two of the clearer demonstrations of RI effects in STM due to item similarity appear in the work of Wickelgren (1966) and Corman \& Wickens (1968). Wickelgren demonstrated $\mathrm{RI}$ as a function of acoustic similarity and Corman and Wickens demonstrated RI as a function of class similarity.

On the basis of a number of experiments (c.g. Conrad, 1964: Wickelgren, 1965, 1966). it has been inferred that representation of material in STM is primarily acoustic ${ }^{l}$ (see Adams. 1967). However, Conrad (1967) has shown that this acoustic representation declines or decays fairly rapidly over a filled retention interval as measured by the decreasing acoustic correspondence between errors in recall and the correct items as the retention interval increases. Given this observation by Conrad, one might expect, therefore, that the degree to which two acoustically similar (AS) verbal units interfere in a STM RI situation is dependent on the time elapsing between the units. The longer the time that elapses between the two successive presentations, the less likely it is that the distinctive acoustic features of the first unit will be present in STM when the second verbal unit is entered.

The present experiment was conducted for two purposes. The first of these was to assess RI effects due to acoustic similarity in an STM situation other than that used by Wickelgren. In Wickelgren's experiments, a list of consonants was

*This research was supported by Research Grant No. 102 from the University of Connecticut Research Foundation to the second author.

$†$ Requests for reprints should be sent to $M$. T. Turvey, Department of Psychology, University of Connecticut, Storrs, Conn. 06268. presented aurally, one at a time, with a tone associated contiguously with one of the consonants. The $S$ was required to recall the tone-associated consonant after a period of time filled with other consonants either AS or acoustically dissimilar $(A D)$ to the critical consonant. The present experiment used a procedure similar to that employed by Corman and Wickens. In the Corman and Wickens experiment, material of the same class (e.g., consonants) as the to-be-remembered material was injected into the filler activity (counting backwards by threes) performed by $S$ during the retention interval of an STM test of the Peterson \& Peterson (1959) variety. That experiment showed that although material of the same class, interpolated between the presentation and recall of the critical memory items, produced $\mathrm{RI}$, the degree of $\mathrm{RI}$ was unaffected by the temporal proximity of the injected similar material to the memory material. The second purpose of the present experiment, therefore, was to determine if the degree of RI produced by AS units was dependent on the time elapsing between the critical memory item and the RI item. Conrad's (1967) data, as argued above, suggest that RI effects should be an inverse function of the time elapsing between AS verbal units.

\section{METHOD}

Ss were undergraduates (14 males, 10 females) drawn from those enrolled in summer courses in introductory psychology at the University of Connecticut. Each $S$ pronounced a pair of tetragrams (consonant letters viewed simultaneously in a single row) that were $\mathrm{AS}$ or $\mathrm{AD}$ and separated by an interpolated task of 2.5 or $18 \mathrm{sec}$ duration. For the AS paradigm, consonants in both tetragrams were selected from those with a final $\overline{\mathrm{e}}$ pronunciation ( $B, C, D, G, P, T, V, Z$ ) or an initial $\breve{e}$ pronunciation $(F, L, M, N, S$, $\mathrm{X})$. In the $\mathrm{AD}$ arrangement, one tetragram was composed of $\overline{\mathrm{e}}$ consonants, the other of ě consonants. No letters were repeated within tetragrams. The four stimulus conditions-AS, $2.5 \mathrm{sec} ; \mathrm{AS}, 18 \mathrm{sec} ; \mathrm{AD}$, $2.5 \mathrm{sec} ; \mathrm{AD}, 18 \mathrm{sec}$-were administered to each of the Ss in a different order such that Ss received all of the 24 possible order permutations. Individual tetragrams appeared equally among the stimulus conditions. Within each stimulus condition, there were equal numbers of $\bar{e}$ and $\bar{c}$ tetragrams.

Ss received a total of 16 experimental STM tests (four consecutive tests for each of the four stimulus conditions) in a single session. The intertest interval was $1 \mathrm{~min}$, in order to reduce $\mathrm{PI}$ effects, with a 3-min intermission approximately halfway through the session. Four practice STM tests preceded the experimental tests. Practice tetragrams were constructed from six acoustically different consonants $(\mathrm{H}, \mathrm{J}$, $\mathrm{Q}, \mathrm{R}, \mathrm{W}, \mathrm{Y})$.

The interpolated task consisted of pronouncing a three-digit number presented visually, and then counting backwards aloud from this number by threes for as long as the three-digit number appeared. STM tests were composed of a sequence of slides delivered by a Kodak Carousel projector and controlled by a tape timer: (1) ready signal of $2-\mathrm{sec}$ duration; (2) first tetragram of $2.5-\mathrm{sec}$ duration; (3) first three-digit number of 2.5- (18-) sec duration; (4) second tetragram of $2.5-\mathrm{sec}$ duration; (5) second three-digit number of 18-(2.5-) sec duration; (6) recall cue of 18-sec duration, which signaled verbal report of the letters of the first tetragram in their correct left-to-right order. All data were recorded by $\mathrm{E}$.

Ss received no instructions as to whether they should or should not attempt to form associations between the letters of first tetragrams and familiar names of people and things or attempt to rehearse first tetragrams during the interpolated task.

\section{RESULTS}

The mean number of correct consonants recalled in their correct tetragram positions per condition (four consecutive STM tests) was the measure of recall. Four recall scores were thus obtained for each $S$, making a total of 96 scores.

As a control, analyses of sex differences and of the effect of order of stimulus conditions were conducted. A $t$ test revealed no differences by sex in total recall per session $(t=0.31, d f=22$, $\mathrm{p}>.05)$. A within-Ss analysis of variance yielded no differences in recall from the first four to the last four STM tests, i.e., no "carry-over" effect between stimulus conditions $(F=1.28, \mathrm{df}=3 / 69, \mathrm{p}>.05)$. Following these checks, a Treatment by Treatment by Ss analysis of variance was applied to the scores. Neither of the 


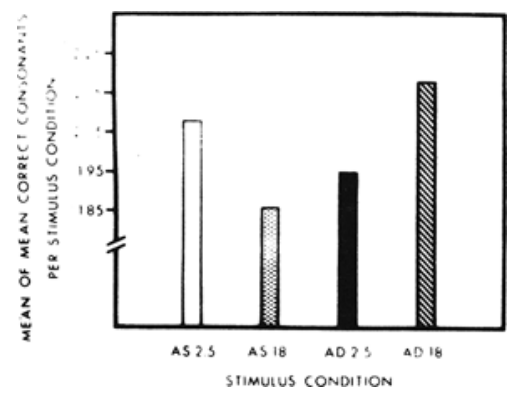

Fig. 1. Level of recall for four stimulus conditions that were acoustically similar (AS) or different (AD), with interpolated tasks of 2.5 or $18 \mathrm{sec}$.

factors, $\mathrm{AS}$ vs $\mathrm{AD}$ or 2.5 - vs $18-\mathrm{sec}$ interpolated task, was statistically significant $(F<1)$. However, as Fig. 1 suggests, the interaction between the two factors was significant $(F=4.51, \mathrm{df}=1 / 23$, $\mathrm{p}<.05$ ), suggesting that with AS stimuli the longer interstimulus interval impaired recall, whereas with $\mathrm{AD}$ stimuli the longer interstimulus interval enhanced recall. However, none of the individual comparisons were significant $(p>.05)$. The analysis also revealed a sizable inter-S variability (mean square $S_{s}=1.73$ for $\mathrm{df}=23 ; \mathrm{cf}$. mean square interaction $=1.20$ for $\mathrm{df}=1$ ).

Inspection of the recall performance across STM tests within conditions indicated that the 1-min intertest interval was effective in that there was no evidence of PI.

\section{DISCUSSION}

On the basis of several sources of data, it was expected that the present experiment would yield a significant RI effect for AS material and perhaps an RI effect that was inversely related - to the time elapsing between successive presentations of AS material. Neither of these expected results was obtained. It could be argued that the absence of a specific RI effect was due to the fact that $S$ was not required to remember the interpolated similar material. However, $S$ was not required to remember the interpolated verbal unit(s) in the experiments previously cited that did obtain specific RI effects (Corman \& Wickens, 1968; Wickelgren, 1966). The negative findings of the present experiment merit consideration in view of the fairly general contention that STM for verbal material is acoustic-based and that forgetting in STM occurs primarily because of acoustic similarity (see Adams, 1967).
The present data question the generality of this contention.

A comparison between the present experiment and experiments that have provided evidence for acoustic interference in STM (e.g., Baddeley, 1966; Wickelgren, $1965,1966)$ suggests that the major difference lies in the mode of presentation of the to-be-remembered and interfering verbal units. Whereas in the present experiment the elements comprising a verbal unit were presented simultaneously, the experiments demonstrating interfering effects of acoustic similarity employed sequential presentation. In a recent study Adams, Thorsheim, \& McIntyre (1969) found clear evidence for intragram acoustic interference when the elements of a verbal unit were presented sequentially and questionable, if not negative, evidence for acoustic interference when the material was presented simultaneously. Also, in the same investigation, Adams et al failed to obtain RI effects as a function of acoustic similarity. In Experiment 2 of their investigation, Adams et al manipulated the acoustic similarity between the memory material, a consonant tetragram presented visually as a unit, and the digits used to fill the retention interval. Recall of the consonant tetragram was unaffected by the degree of acoustic similarity of the digits to the consonant tetragram.

The interaction between length of interpolated task and acoustic similarity of the RI material was opposite that predicted by a consideration of Conrad's (1967) data. However, as the above discussion indicates, Conrad's data reflect the acoustic representation of items presented in the sequential mode. Adams et al observed in one experiment (Experiment 4) that for presentation in the simultaneous mode, intragram acoustic similarity significantly affected performance at longer retention intervals of $10-30 \mathrm{sec}$ but did not affect performance at shorter intervals of $0-5 \mathrm{sec}$. The interaction obtained in the present experiment is somewhat more compatible with this latter datum of Adams et al in that there was a tendency for recall performance to be poorer for the longer interval between AS material.

A surprising amount of forgetting occurred in the present experiment (only $25 \%$ of all the consonant tetragrams were recalled perfectly). This forgetting is even more surprising in view of the fact that PI effects were absent. Clearly, the forgetting cannot be attributed to the specific acoustic features of the injected RI material. It could possibly be attributed to the fact that the consonants of a to-be-remembered tetragram were AS. Reference, however, to the data of Adams et al suggests this as unlikely, and Turvey, Brick. \& Osborn (in press) have shown that in the absence of PI there is no forgetting for consonant trigrams comprised of AS consonants over filled retention intervals in the range of 5 to $25 \mathrm{sec}$.

In conclusion. the present experiment suggests, as does the study of Adams et al. that the role of acoustic similarity in STM requires clarification. Apparently, the effects of acoustic similarity are not as pervasive as is generally conceived. In particular, the present investigation and that of Adams et al suggest caution in adopting the notion that forgetting in all verbal STM situations is due to acoustic similarity.

\section{REFERENCES}

ADAMS, J. A. Human memory. New York: McGraw-Hill. 1967.

ADAMS, J. A., THORSHEIM, H. E., \& McINTYRE, J. S. Item length, acoustic similarity and natural language mediation as variables in short-term memory. Joumal of Experimental Psychology, 1969, 80, 39-46.

BADDFLFY, A. D. Short-term memory for word sequences as a function of acoustic. semantic and tormal similarity. Quarterly Joumal of I. xperimental Psychology, 1966. 18. 362-365.

CONRAD, $R$. Interference or decay over short retention intervals? Journal of Verbal Learning \& Verbal Behavior, 1967, 6, 49-54.

CORMAN, C. D., \& WICKENS, D. D. Retroactive inhibition in short-term memory. Journal of Verbal Learning \& Verbal Behavior, 1968, 7. 16-19.

PETERSON, L. R., \& PETERSON, M. J. Short-term retention of individual verbal items. Journal of Experimental Psychology, 1959, 58, 193-198.

POSNER, M. I. Short term memory systems in human information processing. Acta Psychologica, 1967, 27, 267-284.

TURVEY, M. T., BRICK, P., \& OSBORN, J. Proactive interference in short-term memory as a function of prior item retention interval. Quarterly Journal of Experimental Psychology, in press.

WICKELGREN, W. A. Acoustic similarity and retroactive interference in short-term memory. Journal of Verbal Learning \& Verbal Behavior, $1965,4,53-61$.

WICKELGREN, W. A. Phonemic similarity and interference in short-term memory for single letters. Journal of Experimental Psychology, $1966,71,396-404$.

\section{NOTE}

1. It is understood that the representation may be articulatory rather than acoustic. The single term, acoustic, is employed throughout for the sake of simplicity. 